\title{
The Influence of Generation-skipping Education on Children's Psychological Development
}

\author{
Zhang Liwen \\ School of Preschool and Special Education, Kunming University, Kunming, Yunnan, China, 650200
}

Keywords: generation-skipping education; children’s psychological development; Influence

\begin{abstract}
Along with the industrialization and urbanization process, many parents in rural families go out to work, leaving children to their grandparents. The old people and children form the most common family structure, children educated by grandparents become the left-behind children mainly with family generation-skipping education method. Because there is a distance for grandparents from the demands of modern society in terms of values and lifestyles, it is inevitable that generation-skipping education have a negative impact on children's psychological development. In the face of the problems existing in generation-skipping education, this paper elaborates some psychological problems of children under the condition of generation-skipping education, then analyses the negative effects of generation-skipping education on children and discusses how to make the difference in generation-skipping education. The aim is to improve the effect of generation-skipping education, and let children grow up as healthy and happy as their peers under the condition of generation-skipping education.
\end{abstract}

\section{Introduction}

Generation-skipping education shall mean that the grandparents live together with their grandchildren and assume a certain or major responsibility to the grandchildren. In rural China, both parents go out to work and leave their children at home. Children's grandparents tend to take care of them, and these grandparents are the guardians and reeducations of their children. This education phenomenon, we call it the generation-skipping education.

With the deepening of China's family planning policy, the "4-2-1" family pattern has gradually become the mainstream of Chinese social family pattern. Along with the rapid development of modern social economy and the quickening pace of life, people's ideas have undergone great changes. Many young parents have no time to take care of generation-skipping education children when they go out to work or are too busy to take care of their children. The social research center of China youth daily (2012) surveyed 16,214 people in 31 provinces (districts and cities), and 87.8 percent of respondents admitted that it is common for young people to foster their children through foster care.

\section{The Psychological Problems of Children under Generation-skipping Education}

\subsection{Lack of self-confidence and timid.}

In our life, grandparents habitually arranged everything in their grandchildren's life, essentially depriving them of recognize the outside world and to develop their abilities. When children have problems in their life or study, they often do not have confidence to solve problems and even fear to encounter problems. When problems arise, children tend to lack a sense of independence and independence. The first thing they think about is that they want parents to handle and solve problems for themselves. Generation-skipping education has caused that the children have no confidence and courage to deal with their own problems, and unable to face the ups and downs in the road of growth. And then, it is difficult to adapt to the development of society for the children under the generation-skipping education. 


\subsection{Let children be alone.}

Under the condition of generation-skipping education, children and their parents spend less time with each other, so there is a lack of communication between children and parents. Grandparents often fail to properly discipline and guide them. They fear that children will be hurt unnecessarily, and grandparents often choose a way to care their children such as keeping their children at home. In this way, children who live under the condition of generation-skipping education often choose to avoid the society, because they have less communication with the outside world. It is easy to have some psychological problems, such as introversion, solitude, silence and apathy. Autistic personality is not conducive to the healthy growth of children. Autistic children often have negative emotions in their lives. Once they have a little problem in life or study, they choose to let go.

\subsection{Children's selfish and self-willed personalities}

Generation-skipping education is usually taken care of by grandparents or grandparents. The old man's love for young children is usually indulgent, which is an expression of the old man's love for children. But it is also the main form of developing children's self-centeredness and undermining their good personality. In China, many families are only children or only children. Which leads to a deviation in the care of children. The old man always wants to put the child in the center position, and everything is unconditional to the child. This education method naturally causes children to develop bad personality. For example, we often see grandparents often coax children to eat, write, and usually take the form of material rewards. Over time, when young children find themselves threatening their grandparents with "no eating" and other forms, the child's personal growth has been a problem.

\section{Measures to Solve the Problems of Education in Isolation}

\subsection{The combination of "parent-child education" and " generation-skipping education".}

Parents are the first teachers and the most important teachers. The cultivation of children's spiritual character, moral character, habit style and emotional intelligence is mainly due to parents, parent-child education cannot be replaced. Although there are some advantages of education, it is only a supplement to education, not all of them. So parents and grandparents have to be clear about their education kids, and form the education mode based on our parents. Grandparents should not only brave the idea of some old curing education, but also improve their personal quality, constantly absorbing new knowledge, new ideas and new methods from the new society. Parents should pay more attention to their physical health and pay more attention to the mental health of children. Parents should help children develop correct outlook on life and values.

\subsection{Stick to the science education content.}

We should start from the age characteristics of children's psychological development, so that children can learn and grow meaningfully and effectively. we should promote the comprehensive and harmonious development of children's body, language, cognition, emotion and sociality. When selecting education content, it is not only suitable for children's development needs, but also challenging for children's learning. The education activity of children should have the life and the enlightenment, and enrich the children with the perceptual experience in life. We should mobilize the initiative of children learning in a variety of ways and recognize things in a variety of senses. We should focus on cultivating children's positive and active attitude, strong learning interest, sense of responsibility, self-confidence and other basic qualities.

\subsection{Change family's education environment.}

First, parents should take the necessary responsibilities. Parents can understand the thoughts and behavior of children in time through communication and play with children. It is conducive to the targeted enhancement of education for children and to reduce some of the adverse effects on children. At the same time, it is necessary to strengthen the relationship between children and their 
parents by carrying out activities between parents and children. If parents have long neglected the psychological needs of children to be with their parents, children's mental health is affected. So, we can create a healthy and positive environment to solve all kinds of problems caused by education and promote the healthy growth of children.

\subsection{The school pays attention to children's psychological development.}

Teachers update their education concepts and education methods to cultivate students' interest in learning, independent thinking, self-management and cooperation. Educating children is also an important responsibility of teachers. Students are not passive recipients of knowledge, ideas and values, but active understanding and users. We should give students more time and space to fulfill their tasks, and cultivate their interest in learning and self-efficacy. Teachers should keep learning and constantly update their knowledge reserves, and learn excellent education mode and concept, such as "appreciate education", "advantage education", etc. The school should organize some artistic practice activities to cultivate students' interest, self-expression, organization and management. In addition to the formal educational background education, students should be trained in art education.

\section{Conclusion}

With the change of society and the increasing number of extended families, generation-skipping education has become an important part of family education relative to parent-child education. Although the grandparents have plenty of time and energy and rich education experience in generation-skipping education, they can also liberate their parents' time in the family and relieve the economic pressure of the family. However, the problems caused by it also make us have to face up to the drawbacks of the education. Parent-child education is important for improving the development of children's personality. It can be seen that parent-child education is irreplaceable in family education. So, generation-skipping education is a helpless choice in today's family. But, in order to guarantee the normal parent-child education, the two generations of education have no doubt.

\section{References}

[1] Ahern N R, Kiehl E M, Sole M L, et al. 2006. A review of instruments measuring resilience (Issues in Comprehensive Pediatric Nursing) pp 103-25

[2] Alan Ewert, Aiko Yoshino. 2011. The influence of short-term adventure-based experiences on levels of resilience (Journal of Adventure Generation-skipping education\&Outdoor Learning) pp $35-50$

[3] Alastair A. 2013, Annual Research Review: Resilience and child well-being--public policy implications (Journal of Child Psychology\& Psychiatry\&Allied Disciplines) pp 488-500.

[4] Albert Bandura. 1993. Perceived Self-Efficacy in Cognitive Development and Functioning (Generation-skipping educational Psychologist) 117-148.

[5] Allan B. de Guzman, Eleanor Lourdes C. Tan, Ernestine Faye S. Tan, et al. 2012. Self-Concept, Disposition, and Resilience of Poststroke Filipino Elderly with Residual Paralysis (Generationskipping educational Gerontology) pp 429-442.

[6] Almedom A M. 2013. Resilience: Outcome, Process, Emergence, Narrative (OPEN) theory (On the Horizon) pp 15-23.

[7] Alves D D B. 1985. The Politics of Production: Factory Regimes Under Capitalism and Socialism (American Political Science Review):200-209. 
[8] Andrea J, Segal D L, Coolidge F L, et al. 2009.Religiousness, social support and reasons for living in African American and European American older adults: an exploratory study (Aging\& Mental Health) :753-60. 